\title{
Acidity of titania-supported tungsten or niobium oxide catalysts Correlation with catalytic activity
}

\author{
Thomas Onfroy ${ }^{\mathrm{a}}$, Guillaume Clet $^{\mathrm{a}}$, Saeed B. Bukallah ${ }^{\mathrm{b}}$, \\ Tom Visser ${ }^{\mathrm{c}}$, Marwan Houalla ${ }^{\mathrm{a}, *}$ \\ ${ }^{a}$ Laboratoire Catalyse et Spectrochimie, UMR CNRS 6506, ENSICAEN-Université de Caen, 6 Bd. du Maréchal Juin, \\ 14050 Caen Cedex, France \\ ${ }^{\mathrm{b}}$ Surface Sciences and Applied Catalysis, Faculty of Sciences, Chemistry Dept., UAE University, \\ P.O. Box 17551, Al-Ain, UAE \\ ${ }^{\mathrm{c}}$ Department of Inorganic Chemistry and Catalysis, Debye Institute, Utrecht University, Sorbonnelaan 16, \\ 3584CA Utrecht, The Netherlands
}

Received 20 July 2005; received in revised form 13 September 2005; accepted 22 September 2005 Available online 9 November 2005

\begin{abstract}
The acidity of catalytic systems based on tungsten oxide or niobium oxide supported on titania was compared. Two series with metal contents up to 3.6 atom nm ${ }^{-2}$ were prepared by incipient wetness impregnation of the titania support with ammonium metatungstate or niobium oxalate solutions. Characterization of both systems by X-ray diffraction and Raman spectroscopy studies did not show evidence of bulk metal oxide formation. The acidity was monitored by adsorption of 2,6-dimethylpyridine (2,6-lutidine) followed by infrared spectroscopy. The catalytic activity was tested for the reaction of isopropanol dehydration.

At a reaction temperature of $403 \mathrm{~K}, \mathrm{WO}_{x} / \mathrm{TiO}_{2}$ catalysts were inactive for a surface density of $\mathrm{W} \leq 1.2 \mathrm{~W}$ atom nm ${ }^{-2}$. Above this loading, the activity increased progressively with increasing W content. Similar evolution was observed for the abundance of relatively strong Brønsted acid sites (i.e. able to retain lutidine at $573 \mathrm{~K}$ ). In contrast, $\mathrm{NbO}_{x} / \mathrm{TiO}_{2}$ catalysts were essentially inactive at this reaction temperature and a higher reaction temperature $(473 \mathrm{~K})$ was required to reach a comparable catalytic activity. No threshold of Nb loading for the development of catalytic activity was observed. Similar behavior was evidenced for the abundance of medium strength Brønsted acid sites (able to retain lutidine at $523 \mathrm{~K}$ ). For both systems, a direct correlation between the catalytic activity and the abundance of Brønsted acid sites was observed.
\end{abstract}

(C) 2005 Elsevier B.V. All rights reserved.

Keywords: Acidity; Titania-supported tungsten oxide; Titania-supported niobium oxide; Propanol dehydration; 2,6-Dimethyl pyridine adsorption

\section{Introduction}

Supported metal oxides of the groups 5 and 6 often show acidic properties. To understand the genesis of the acidity, it is of interest to investigate the role of the support and the supported phase in determining the nature, force and abundance of the acid sites. Supported W oxides have been widely studied for acid-catalyzed reactions such as alkenes [1,2] or alkanes [35] isomerization. Several acid-catalyzed reactions were also reported for the corresponding Nb-based systems [6-11].

\footnotetext{
* Corresponding author. Tel.: +332 315673 51; fax: +332 31452822 . E-mail address: Marwan.Houalla@ensicaen.fr (M. Houalla).
}

In previous studies, we have shown that both tungsten $[12,13]$ and niobium $[14,15]$ oxides supported on zirconia induce the formation of Brønsted acid sites. For both systems significant formation of Brønsted acid sites only occurs above a threshold of $\mathrm{W}$ or $\mathrm{Nb}$ surface density of about 1.2 atom nm ${ }^{-2}$. Similar evolution was observed for the catalysts activity for propanol dehydration. However, a large difference in the catalytic performance was observed, which was attributed to the presence of relatively stronger Brønsted acid sites for the W system.

The purpose of the present paper is to examine how the above noted characteristics of both systems (presence of a threshold of $\mathrm{W}$ or $\mathrm{Nb}$ loading for the appearance of Brønsted acid sites; evolution of the acidity with the surface density of deposited metal oxide; correlation with activity for acid- 
catalyzed reaction) are affected by the nature of the support. Towards this objective, the surface structure and catalytic properties of titania-supported $\mathrm{W}$ and $\mathrm{Nb}$ systems will be examined. These systems have also been shown to exhibit acidic properties [5,10,11,16-21]. Characterization of both systems will be conducted by X-ray diffraction and Raman spectroscopy studies. The acidity will be monitored by adsorption of 2,6-dimethylpyridine (2,6-lutidine or DMP) followed by infrared spectroscopy. The results will be correlated with catalytic activity for the reaction of isopropanol dehydration.

\section{Experimental}

\subsection{Preparation of the solids}

The titania support (Degussa; P-25) was previously calcined at $823 \mathrm{~K}$ for the $\mathrm{W}$ system and at $673 \mathrm{~K}$ for the niobiumcontaining solids. Supported catalysts were prepared by incipient wetness impregnation of the $\mathrm{TiO}_{2}$ support with a solution of the metal precursor. For $\mathrm{WO}_{x} / \mathrm{TiO}_{2}$, the support was impregnated with an aqueous solution of ammonium metatungstate $\left(\left(\mathrm{NH}_{4}\right)_{6} \mathrm{H}_{2} \mathrm{~W}_{12} \mathrm{O}_{40}\right)$ then dried at $393 \mathrm{~K}$ for $16 \mathrm{~h}$ and calcined in air at $773 \mathrm{~K}$ for $16 \mathrm{~h}$. For $\mathrm{NbO}_{x} / \mathrm{TiO}_{2}$, the support was impregnated with a mixture of $7 \mathrm{wt} \%$ of niobium (V) oxalate and $93 \mathrm{wt} \%$ of oxalic acid diluted in the required amount of water, dried at $393 \mathrm{~K}$ for $16 \mathrm{~h}$ and calcined in air at $723 \mathrm{~K}$ for $16 \mathrm{~h}$.

Supported tungsten and niobium oxides will be designated as $\mathrm{W} x \mathrm{~T}$ and $\mathrm{Nby} \mathrm{T}$, respectively, where $x$ and $y$ represent the metal $(\mathrm{W}$ or $\mathrm{Nb})$ density in atom $\mathrm{nm}^{-2}$

\subsection{BET surface area}

Nitrogen adsorption was measured at $77 \mathrm{~K}$ with an automatic adsorptiometer (Micromeritics ASAP 2000). The samples were pre-treated at $573 \mathrm{~K}$ for $2 \mathrm{~h}$ under vacuum. The surface areas were determined from adsorption values at five relative pressures $\left(P / P_{0}\right)$ ranging from 0.05 to 0.2 using the BET method. The pore volumes were determined from the total amount of $\mathrm{N}_{2}$ adsorbed between $P / P_{0}=0.05$ and 0.98 .

\subsection{X-ray diffraction}

X-ray powder diffraction spectra were recorded using a Philips X'pert diffractometer with copper anode $\left(\mathrm{K} \alpha_{1}=0.15405 \mathrm{~nm}\right)$ and a scanning rate of $0.025^{\circ} \mathrm{s}^{-1}$. The anatase/rutile composition of the support was determined from the intensities of the peaks $I_{\mathrm{A}}$ and $I_{\mathrm{R}}$ characteristics of the

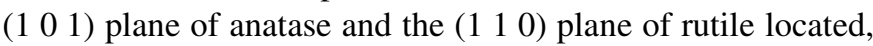
respectively, at $2 \theta=25.4^{\circ}$ and $27.5^{\circ}$, using the following formula [22]:

$A=\frac{1}{1+1.26 \frac{I_{\mathrm{R}}}{I_{\mathrm{A}}}}$

where $A$ designates the fraction of the support present as anatase.

\subsection{Raman spectroscopy}

Raman characterization was performed under ambient conditions. The spectra (20 scans of $10 \mathrm{~s}$; resolution $2 \mathrm{~cm}^{-1}$ ) were recorded with a dispersive Raman (Kaiser) equipped with diode laser source $(\lambda=532 \mathrm{~nm})$ and a CCD camera.

\subsection{Infrared spectroscopy}

The samples, pressed into pellets $\left(\sim 20 \mathrm{mg}\right.$ for a $2 \mathrm{~cm}^{2}$ pellet), were first heated under vacuum at $623 \mathrm{~K}$ for $30 \mathrm{~min}$. This first treatment was followed by a treatment in $\mathrm{O}_{2}$ $\left(P_{\text {equilibrium }}=13.3 \mathrm{kPa}\right)$ for $1 \mathrm{~h}$, and evacuation for $30 \mathrm{~min}$ at $623 \mathrm{~K}$ before cooling down to room temperature $(295 \mathrm{~K})$.

IR spectra were recorded with a Nicolet Magna 550 FT-IR spectrometer (resolution: $4 \mathrm{~cm}^{-1}, 128$ scans). All the spectra shown in the present study were obtained after subtraction of the spectra of evacuated sample and normalization for $100 \mathrm{mg}$ of the solid. 2,6-Dimethylpyridine was introduced at $295 \mathrm{~K}\left(P_{\text {equili- }}\right.$ brium $=133 \mathrm{~Pa})$, after activation. Spectra were then recorded after desorption from 323 to $573 \mathrm{~K}$. The cell was evacuated at the desorption temperature until a residual pressure below $6.7 \times 10^{-4} \mathrm{~Pa}$. The abundance of Brønsted acid sites titrated by 2,6-dimethyl pyridine was estimated from the sum of the bands at 1643 and $1627 \mathrm{~cm}^{-1}$ (respectively, $v_{8 a}$ and $v_{8 b}$ vibrations) using a previously determined [23] value of the integrated molar absorption coefficient $(\varepsilon)$ of the vibrations

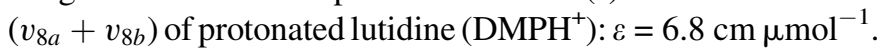

\subsection{Catalytic activity}

The catalytic conversion of propan-2-ol (isopropanol) was measured in a fixed bed flow reactor. Hundred milligrams of

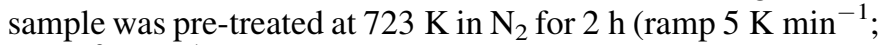
$\left.60 \mathrm{~cm}^{3} \mathrm{~min}^{-1}\right)$. The reaction was performed at atmospheric pressure with $\mathrm{N}_{2}$ as carrier gas $\left(P_{\text {isopropanol }}=1.23 \mathrm{kPa}\right.$; $\mathrm{WHSV}=17.3 \mathrm{mmol} \mathrm{h}^{-1} \mathrm{~g}^{-1}$; total flow rate $=60 \mathrm{~cm}^{3} \mathrm{~min}^{-1}$ ) at $403 \mathrm{~K}$ for $\mathrm{WO}_{x} / \mathrm{TiO}_{2}$ and $473 \mathrm{~K}$ for $\mathrm{NbO}_{x} / \mathrm{TiO}_{2}$. Reactants and products were analyzed with an on line G.C. (HP 5890 Series II) equipped with a capillary column (CP WAX 52 CB) and a FID detector.

\section{Results}

\subsection{Preparation of the catalysts}

Both $\mathrm{WO}_{x} / \mathrm{TiO}_{2}$ and $\mathrm{NbO}_{x} / \mathrm{TiO}_{2}$ series were prepared by incipient wetness impregnation of the titania support with a solution of the metal salts deposited on titania. Two series of

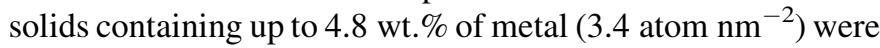
obtained. The characteristics of the solids are summarized in Table 1 for the tungsten-containing solids and in Table 2 for the niobium-containing system. $\mathrm{TiO}_{2}$ had a surface area of $46 \mathrm{~m}^{2} \mathrm{~g}^{-1}$ and a pore volume equal to $0.24 \mathrm{~cm}^{3} \mathrm{~g}^{-1}$. For all the supported solids, the specific surface area of the support was not modified significantly on metal addition. The surface density was, thus, expressed as the number of atoms of $\mathrm{Nb}$ or $\mathrm{W}$ 
Table 1

Characteristics of $\mathrm{WO}_{x} / \mathrm{TiO}_{2}$ catalysts

\begin{tabular}{|c|c|c|c|c|c|c|c|}
\hline & \multicolumn{7}{|c|}{ Sample } \\
\hline & $\mathrm{TiO}_{2}$ & W0.6 T & $\mathrm{W} 1.1 \mathrm{~T}$ & $\mathrm{~W} 1.7 \mathrm{~T}$ & $\mathrm{~W} 2.3 \mathrm{~T}$ & $\mathrm{~W} 2.8 \mathrm{~T}$ & W3.4 T \\
\hline $\mathrm{W}(\mathrm{wt} . \%)$ & 0.00 & 0.80 & 1.60 & 2.40 & 3.20 & 4.00 & 4.80 \\
\hline $\mathrm{W}\left(\right.$ atom nm ${ }^{-2}$ ) & 0.0 & 0.6 & 1.1 & 1.7 & 2.3 & 2.8 & 3.4 \\
\hline$\%$ Monolayer & 0 & 12 & 22 & 35 & 47 & 57 & 69 \\
\hline Surface area $\left(\mathrm{m}^{2} \mathrm{~g}^{-1}\right)$ & 46 & 47 & 47 & 47 & 47 & 47 & 46 \\
\hline
\end{tabular}

Table 2

Characteristics of $\mathrm{NbO}_{x} / \mathrm{TiO}_{2}$ catalysts

\begin{tabular}{|c|c|c|c|c|c|}
\hline & \multicolumn{5}{|c|}{ Sample } \\
\hline & $\mathrm{TiO}_{2}$ & $\mathrm{Nb} 0.6 \mathrm{~T}$ & $\mathrm{Nb} 1.2 \mathrm{~T}$ & $\mathrm{Nb} 2.4 \mathrm{~T}$ & $\mathrm{Nb} 3.6 \mathrm{~T}$ \\
\hline $\mathrm{Nb}$ (wt.\%) & 0.00 & 0.48 & 0.95 & 1.88 & 2.79 \\
\hline $\mathrm{Nb}_{2} \mathrm{O}_{5}$ (wt.\%) & 0.00 & 0.69 & 1.36 & 2.69 & 3.99 \\
\hline $\mathrm{Nb}\left(\right.$ atom nm${ }^{-2}$ ) & 0.0 & 0.6 & 1.2 & 2.4 & 3.6 \\
\hline \% Monolayer & 0 & 10 & 20 & 40 & 60 \\
\hline Surface area $\left(\mathrm{m}^{2} \mathrm{~g}^{-1}\right)$ & 46 & 45 & 46 & 46 & 48 \\
\hline Pore volume $\left(\mathrm{cm}^{3} \mathrm{~g}^{-1}\right)$ & 0.24 & 0.24 & 0.23 & 0.23 & 0.26 \\
\hline$\%$ Anatase & 62 & 59 & 60 & 62 & 61 \\
\hline
\end{tabular}

per $\mathrm{nm}^{2}$ of the titania support. For $\mathrm{WO}_{x} / \mathrm{TiO}_{2}$, the theoretical coverage was calculated assuming that a full monolayer corresponds to $4.9 \mathrm{~W}$ atom $\mathrm{nm}^{-2}[24,25]$. For $\mathrm{NbO}_{x} / \mathrm{TiO}_{2}$, the theoretical coverage was estimated considering that each $\mathrm{Nb}_{2} \mathrm{O}_{5}$ unit occupies $0.32 \mathrm{~nm}^{2}$ [26].

\subsection{X-ray diffraction}

The diffraction pattern of $\mathrm{TiO}_{2}$ showed two main peaks at $2 \theta=25.4^{\circ}$ and $27.5^{\circ}$, characteristic, respectively, of the $\left(\begin{array}{lll}1 & 0 & 1\end{array}\right)$ plane of anatase and the (1 110$)$ plane of rutile [22,27]. The composition of the support was $60 \%$ anatase $-40 \%$ rutile. The percentage of anatase in the support reported in Tables 1 and 2 was estimated from the relative intensity of these peaks (see Section 2). No significant change in the composition of the titania support (anatase/rutile ratio) was observed on deposition of $\mathrm{W}$ or $\mathrm{Nb}$. In addition, no peaks, which can be attributed to crystalline $\mathrm{WO}_{3}$ or $\mathrm{Nb}_{2} \mathrm{O}_{5}$, were evidenced.

\subsection{Raman spectroscopy}

Figs. 1 and 2 show the Raman spectra for the supported $\mathrm{WO}_{x} / \mathrm{TiO}_{2}$ and $\mathrm{NbO}_{x} / \mathrm{TiO}_{2}$ systems, respectively. Also included in these figures is the Raman spectrum of the titania support. The bands located at 396, 515 and $636 \mathrm{~cm}^{-1}$ are characteristic of anatase (A); that observed at $447 \mathrm{~cm}^{-1}$ and the shoulder at ca. $605 \mathrm{~cm}^{-1}$ are ascribed to rutile (R) $[20,26]$. The band at $794 \mathrm{~cm}^{-1}$ is due to the first overtone vibration of the anatase band at $396 \mathrm{~cm}^{-1}$ [28]. In accord with XRD results, the addition of metal oxide on the titania support did not modify significantly the relative intensities of these bands, indicating that the composition of the support was not affected by the deposition of the supported phase.

For W-containing solids (Fig. 1), Raman spectra show the presence of a band between 950 and $975 \mathrm{~cm}^{-1}$ characteristic of surface W species [19,20,29-31] and attributed to the vibration of $\mathrm{W}=\mathrm{O}$ bond in hydrated mono-oxotungstate species on titania surface [18,31]. No bands indicative of the presence of bulk $\mathrm{WO}_{3}$ (bands at 806 and $713 \mathrm{~cm}^{-1}$ ) were detected.

As suggested by XRD results, Raman spectra of $\mathrm{NbO}_{x} / \mathrm{TiO}_{2}$ samples (Fig. 2) did not indicate the presence of $\mathrm{Nb}_{2} \mathrm{O}_{5}$ (a band at ca. $675 \mathrm{~cm}^{-1}$ [32] for hexagonal $\mathrm{Nb}_{2} \mathrm{O}_{5}$ and around $260 \mathrm{~cm}^{-1}$ for monoclinic $\mathrm{Nb}_{2} \mathrm{O}_{5}$ [32,33]). Niobic acid $\left(\mathrm{Nb}_{2} \mathrm{O}_{5} \cdot n \mathrm{H}_{2} \mathrm{O}\right)$ is characterized by a wide band around $650 \mathrm{~cm}^{-1}$ [26,32]. The detection of this band in titania-supported catalysts is hindered by the presence of a large band at $636 \mathrm{~cm}^{-1}$ due to anatase.

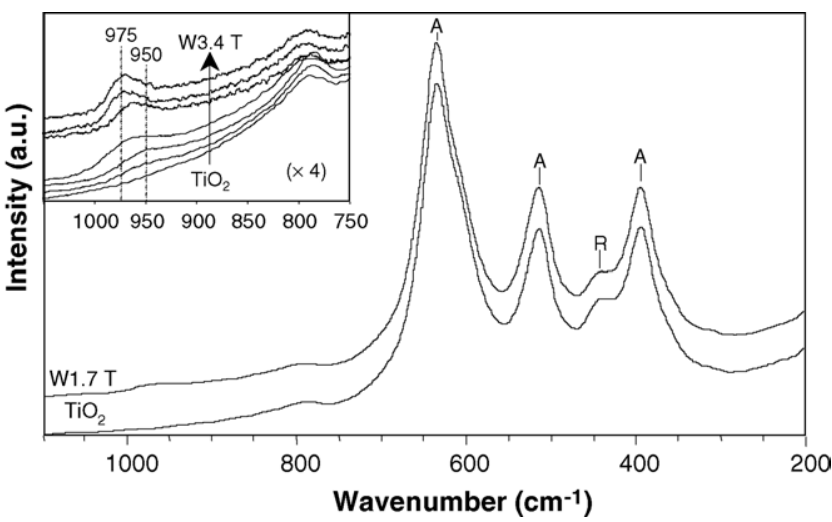

Fig. 1. Raman spectra of $\mathrm{TiO}_{2}$ and $\mathrm{W} 1.7 \mathrm{~T}$ catalysts under ambient conditions, normalized to the $636 \mathrm{~cm}^{-1}$ band. Inset: Enlargement of the $1050-750 \mathrm{~cm}^{-1}$ region for $\mathrm{TiO}_{2}$ and $\mathrm{WO}_{x} / \mathrm{TiO}_{2}$ solids. 


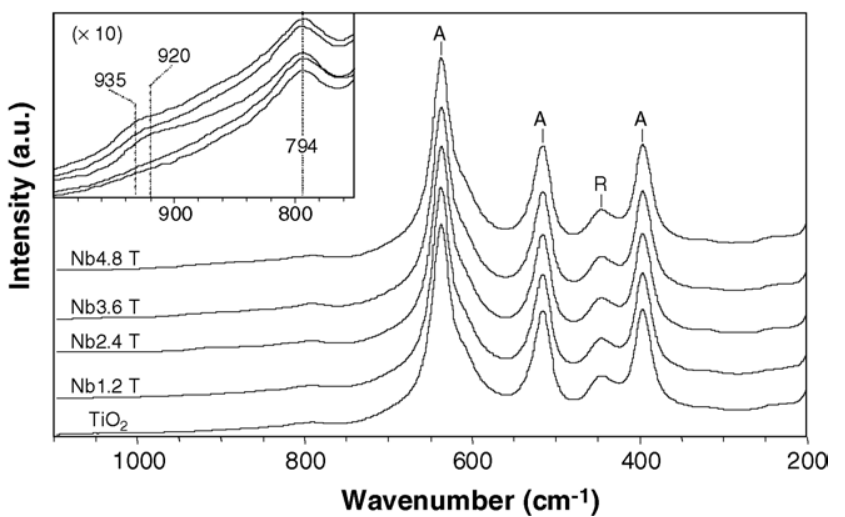

Fig. 2. Raman spectra of $\mathrm{NbO}_{x} / \mathrm{TiO}_{2}$ catalysts under ambient conditions, normalized to the $636 \mathrm{~cm}^{-1}$ band, between 1100 and $200 \mathrm{~cm}^{-1}$. Inset: Enlargement of the $1000-750 \mathrm{~cm}^{-1}$ region.

Subtracting the contribution of the titania support as proposed by Pittman et al. [26] did not reveal the presence of the niobic acid phase.

Analysis of the Raman spectra in the $750-1100 \mathrm{~cm}^{-1}$ region showed the presence of a weak and broad band located at ca. $920 \mathrm{~cm}^{-1}$ for low $\mathrm{Nb}$ loadings which shifts towards $935 \mathrm{~cm}^{-1}$ with increasing metal content. This band was attributed to a hydrated niobate surface species [34].

\subsection{Infrared spectroscopy}

Fig. 3a shows the infrared spectra for the titania support following adsorption of 2,6-lutidine (at $133 \mathrm{~Pa}$ ) and desorption at $423 \mathrm{~K}$. In agreement with Lahousse et al. [35] and Travert et al. [36], a doublet is observed at 1643 and $1627 \mathrm{~cm}^{-1}$ characteristic of the $v_{8 a}$ and $v_{8 b}$, vibrations of protonated lutidine and due to Brønsted acid sites, and a band at $1614 \mathrm{~cm}^{-1}$ characteristic of lutidine adsorbed on Lewis acid sites. Also shown in Fig. 3a are the infrared spectra of $\mathrm{WO}_{x} /$ $\mathrm{TiO}_{2}$ under the same conditions. It can be readily seen that the abundance of Lewis acid sites decreased with increasing W content. This trend is accompanied by a progressive increase in the number of Brønsted acid sites. Fig. $3 b$ shows the evolution of these Brønsted acid sites after desorption at 423, 523 and $573 \mathrm{~K}$. At 423 and $523 \mathrm{~K}$, the concentration of these sites increased linearly with increasing $\mathrm{W}$ surface density up to $3.4 \mathrm{~W}$ atom $\mathrm{nm}^{-2}$. However, at the latter temperature, the Brønsted acidity of the titania support was too weak to retain the probe. Following desorption at $573 \mathrm{~K}$, only the solids containing more than $1.1 \mathrm{~W}$ atom $\mathrm{nm}^{-2}$ showed Brønsted acid sites sufficiently strong to retain lutidine. For higher loadings, the abundance of these sites increased linearly with $\mathrm{W}$ content.

The infrared spectra of $\mathrm{NbO}_{x} / \mathrm{TiO}_{2}$ catalysts following adsorption of lutidine and desorption at $423 \mathrm{~K}$ are shown on Fig. 4a. As for the $\mathrm{W}$ system, $\mathrm{Nb}$ addition decreases the number of Lewis acid sites and brings about a progressive increase in the abundance of Brønsted acid sites. The evolution of the Brønsted sites with $\mathrm{Nb}$ surface density following desorption at 423, 523 and $573 \mathrm{~K}$ is depicted in Fig. 4b. At 423 and $523 \mathrm{~K}$, the observed behavior was similar to that of the corresponding $\mathrm{W}$ system. However, following desorption at $573 \mathrm{~K}$, in contrast with the W-based catalysts, no bands characteristic of protonated lutidine were detected.

\subsection{Catalytic activity}

Both series of solids were tested for the dehydration of propan-2-ol. In this reaction, the formation of propene is correlated to the acidic character. Due to a large difference of activity, W-containing solids were tested at $403 \mathrm{~K}$, whereas the activity of $\mathrm{Nb}$-containing solids was measured at a higher reaction temperature $(473 \mathrm{~K})$. The titania support was inactive at $403 \mathrm{~K}$ and only slightly active at $473 \mathrm{~K}$ (propene formation rate of $0.1 \mathrm{mmol} \mathrm{h}^{-1} \mathrm{~g}^{-1}$ ), which is coherent with previous results by Lahousse et al. [35].

Propene and diisopropyl ether were the only products obtained, acetone was not observed. Hence, both series show an acidic character. For W-based system, at $403 \mathrm{~K}$, the selectivity to propene was about $90 \%$. With $\mathrm{Nb}$-containing solids, at
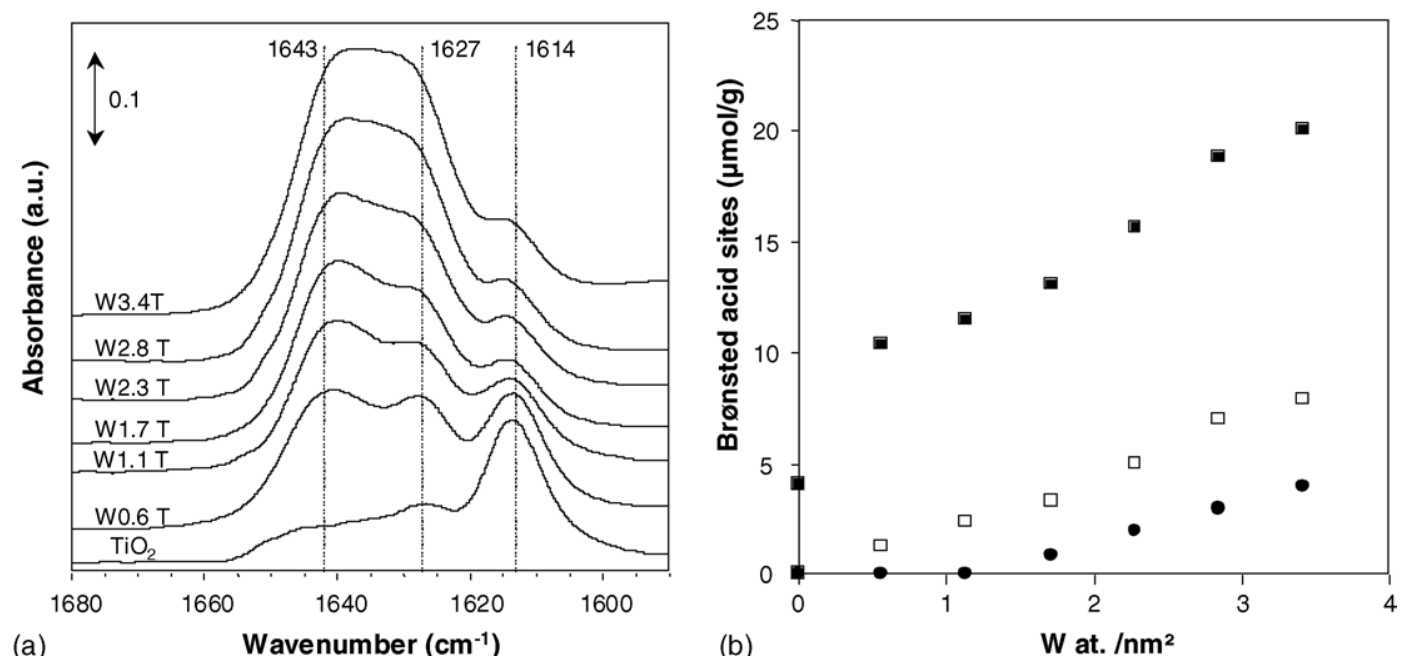

Fig. 3. Adsorption of lutidine on $\mathrm{WO}_{x} / \mathrm{TiO}_{2}$ catalysts: (a) IR spectra of $\mathrm{TiO}_{2}$ and $\mathrm{WO}_{x} / \mathrm{TiO}_{2}$ after desorption of lutidine at $423 \mathrm{~K}$ (spectra normalized for $100 \mathrm{mg}$ ); (b) evolution of the abundance of Brønsted acid sites vs. W content, following desorption of lutidine at $423 \mathrm{~K}$

$(\mathbf{\square}), 523 \mathrm{~K}(\square)$ and $573 \mathrm{~K}(\bullet)$ 

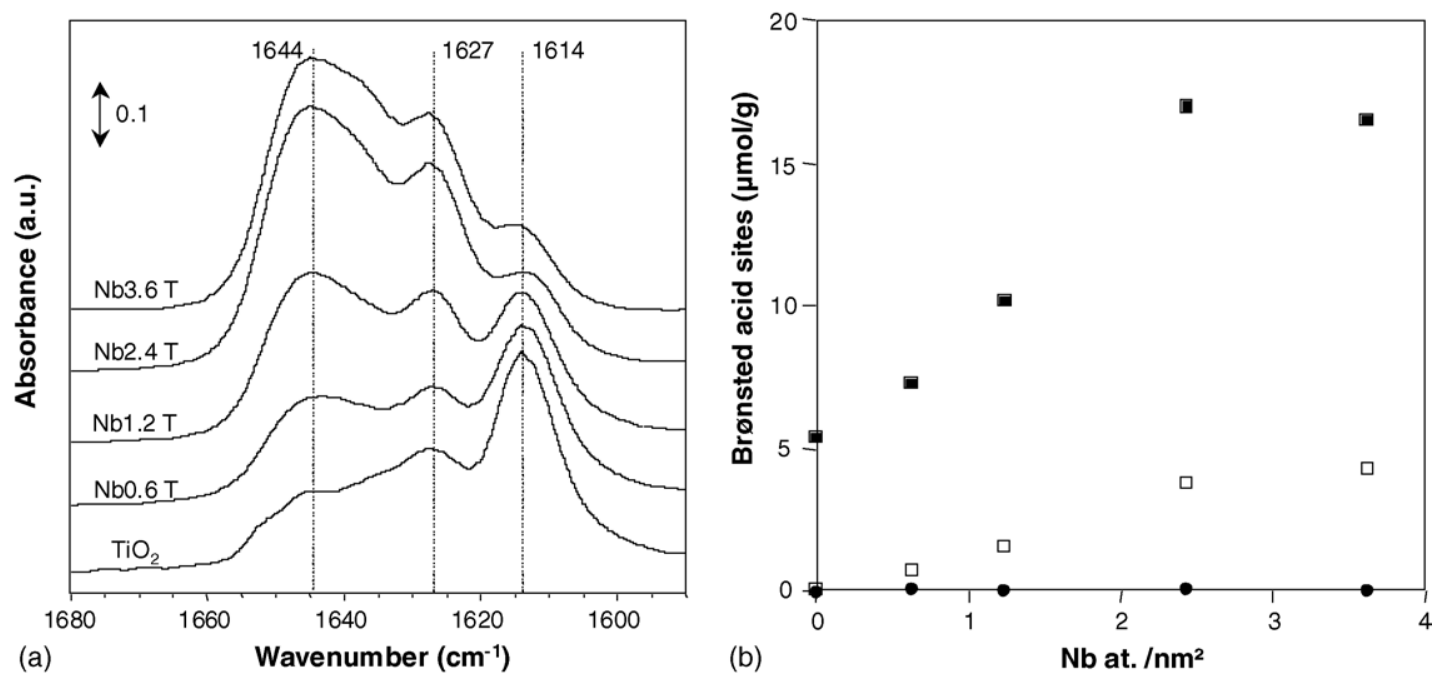

Fig. 4. Adsorption of lutidine on $\mathrm{NbO}_{x} / \mathrm{TiO}_{2}$ : (a) IR spectra of $\mathrm{TiO}_{2}$ and $\mathrm{NbO}_{x} / \mathrm{TiO}_{2}$ after desorption of lutidine at $423 \mathrm{~K}$ (spectra normalized for $100 \mathrm{mg}$ ); (b) evolution of the abundance of Brønsted acid sites vs. Nb content, after desorption of lutidine at $423 \mathrm{~K}(\boldsymbol{\square}), 523 \mathrm{~K}(\square)$ and $573 \mathrm{~K}(\bullet)$.

$473 \mathrm{~K}$, propene, which is thermodynamically favored at high temperature, was the only product detected.

Fig. 5 presents the propene formation rate for both $\mathrm{WO}_{x} / \mathrm{TiO}_{2}$ and $\mathrm{NbO}_{x} / \mathrm{TiO}_{2}$ series. At $403 \mathrm{~K}$, W-containing solids were inactive below a $\mathrm{W}$ surface density of $1.1 \mathrm{~W}$ atom $\mathrm{nm}^{-2}$. For higher $\mathrm{W}$ loadings, the activity developed progressively to reach $4.5 \mathrm{mmol} \mathrm{h}^{-1} \mathrm{~g}^{-1}$ for W3.4 $\mathrm{T}$ (Fig. 5a). For $\mathrm{NbO}_{x} / \mathrm{TiO}_{2}$ catalysts (Fig. 5b), as noted above, the titania support exhibited some activity at $473 \mathrm{~K}$. Nb deposition led to a steady increase in activity. In variance with the $\mathrm{WO}_{x} / \mathrm{TiO}_{2}$ system, no apparent minimum of $\mathrm{Nb}$ loading was required for the development of the activity.

\section{Discussion}

\section{1. $\mathrm{WO}_{x} / \mathrm{TiO}_{2}$}

Lutidine adsorption results monitored by infrared spectroscopy indicated that the abundance of Lewis acid sites initially

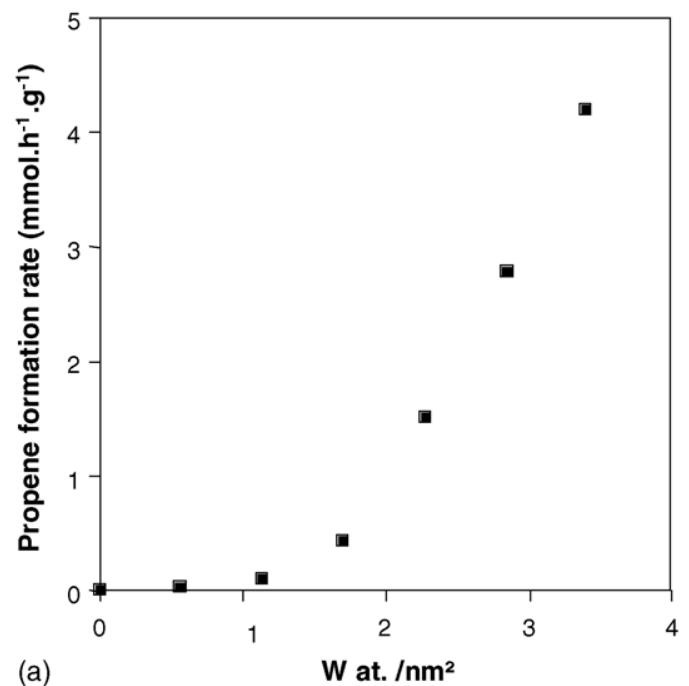

present on the titania support decreases on deposition of tungsten. This trend is accompanied by the formation of Brønsted acid sites. The detection of Brønsted acid sites in $\mathrm{WO}_{x} / \mathrm{TiO}_{2}$ is in agreement with previous infrared studies of ammonia [16-20], pyridine [18] and CO adsorption [5,16].

Brønsted acid sites were evidenced in all W-containing solids following desorption of lutidine at 423 and $523 \mathrm{~K}$. The concentration of these sites appears to increase progressively with increasing $\mathrm{W}$ content. However, after desorption at $573 \mathrm{~K}$, Brønsted acid sites that are sufficiently strong to retain lutidine at this temperature were only detected for solids above a threshold of $\mathrm{W}$ surface density equal to $1.1 \mathrm{~W}$ atom $\mathrm{nm}^{-2}$.

Consistent with high temperature lutidine desorption data, a minimum of $\mathrm{W}$ loading of $1.1 \mathrm{~W}$ atom $\mathrm{nm}^{-2}$ was required for the onset of catalytic activity for isopropanol dehydration at $403 \mathrm{~K}$. Further, analysis of the activity results indicated that this threshold of $\mathrm{W}$ coincides with that observed for the formation of relatively strong Brønsted acid sites. The overall evolution of

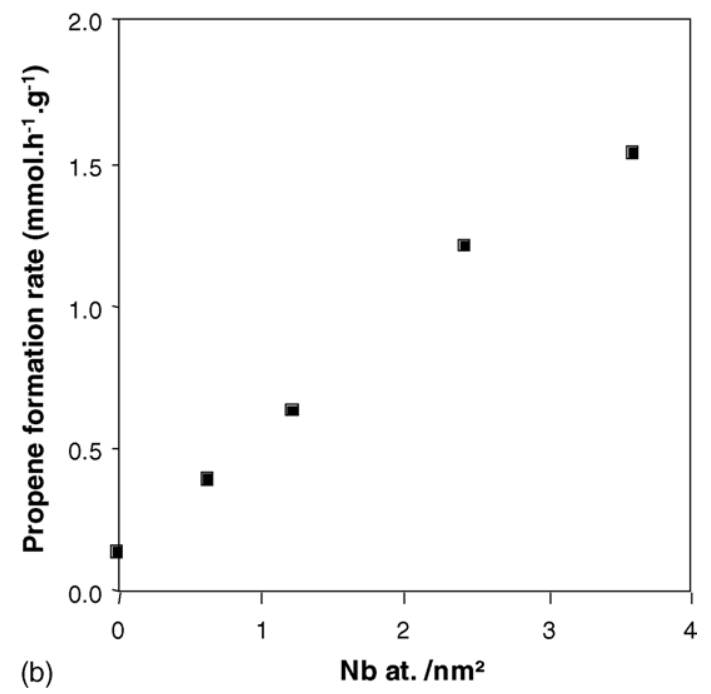

Fig. 5. Propene formation rate vs. metal loading: (a) $\mathrm{WO}_{x} / \mathrm{TiO}_{2}$ catalysts $(T=403 \mathrm{~K})$ and (b) $\mathrm{NbO}_{x} / \mathrm{TiO}_{2}$ catalysts $(T=473 \mathrm{~K})$. 

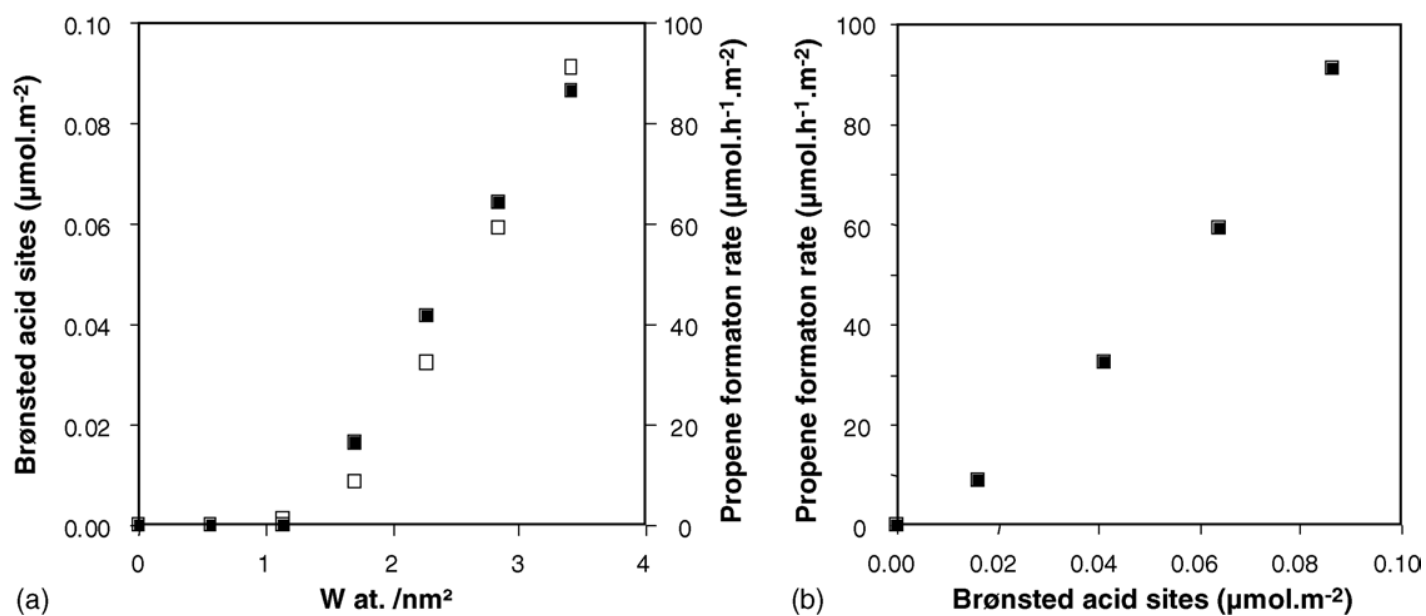

Fig. 6. (a) Propene formation rate at $403 \mathrm{~K}(\square)$ and abundance of strong Brønsted acid sites determined by desorption of lutidine at $573 \mathrm{~K}(\boldsymbol{\square})$ vs. W density of WO $\mathrm{O}_{x}$ $\mathrm{TiO}_{2}$ catalysts; (b) propene formation rate vs. abundance of Brønsted acid sites for $\mathrm{WO}_{x} / \mathrm{TiO}_{2}$ catalysts.

the catalytic activity as a function of $\mathrm{W}$ surface density was similar to that observed for Brønsted acidity detected by lutidine desorption experiments at $573 \mathrm{~K}$ (Fig. 6a). Catalysts containing less than $1.1 \mathrm{~W}$ atom $\mathrm{nm}^{-2}$ were essentially inactive. Above this loading, propene formation activity developed progressively with $\mathrm{W}$ content. The presence of a threshold of $\mathrm{W}$ content for the development of activity in an acid-catalyzed reaction (cumene dealkylation) was reported for solids obtained by impregnation of titanium oxyhydroxide and calcined at $773 \mathrm{~K}$ [37]. To the best of our knowledge, no such behavior was reported for catalysts obtained by impregnation of titania. It was, however, observed for another type of reaction, i.e. the selective catalytic reduction (SCR) of NO [20] where the Brønsted acidity of the solids has been shown to be an important parameter in determining the overall catalytic performance.

\section{2. $\mathrm{NbO}_{x} / \mathrm{TiO}_{2}$}

As observed in the case of W-based systems, Brønsted acid sites were also evidenced in $\mathrm{NbO}_{x} / \mathrm{TiO}_{2}$ catalysts. For a given
$\mathrm{Nb}$ surface density, the drastic decrease in the abundance of these sites on increasing the desorption temperature from 423 to $523 \mathrm{~K}$ indicates that most of the sites titrated at $423 \mathrm{~K}$ are weak in nature. The absence of bands characteristic of protonated lutidine following desorption at $573 \mathrm{~K}$ implies that essentially moderate Brønsted acidities are measured following desorption at $523 \mathrm{~K}$. The weak and moderate Brønsted acidity inferred from lutidine desorption results at 423 or $523 \mathrm{~K}$, increased in abundance with $\mathrm{Nb}$ loading. The detection of relatively large amounts of Brønsted acid sites is in variance with previous reports by Datka et al. [21] relative to pyridine adsorbed on supported $\mathrm{Nb}$ systems where no significant Brønsted acid sites formation had been observed. However, as in the case of zirconia [14,15], this apparent discrepancy can be readily explained by the use in the present study of lutidine which is inherently a more sensitive probe molecule than pyridine for the detection of Brønsted acid sites [23].

Fig. 7a shows the evolution of the number of Brønsted acid sites measured by desorption of lutidine at $523 \mathrm{~K}$, compared to
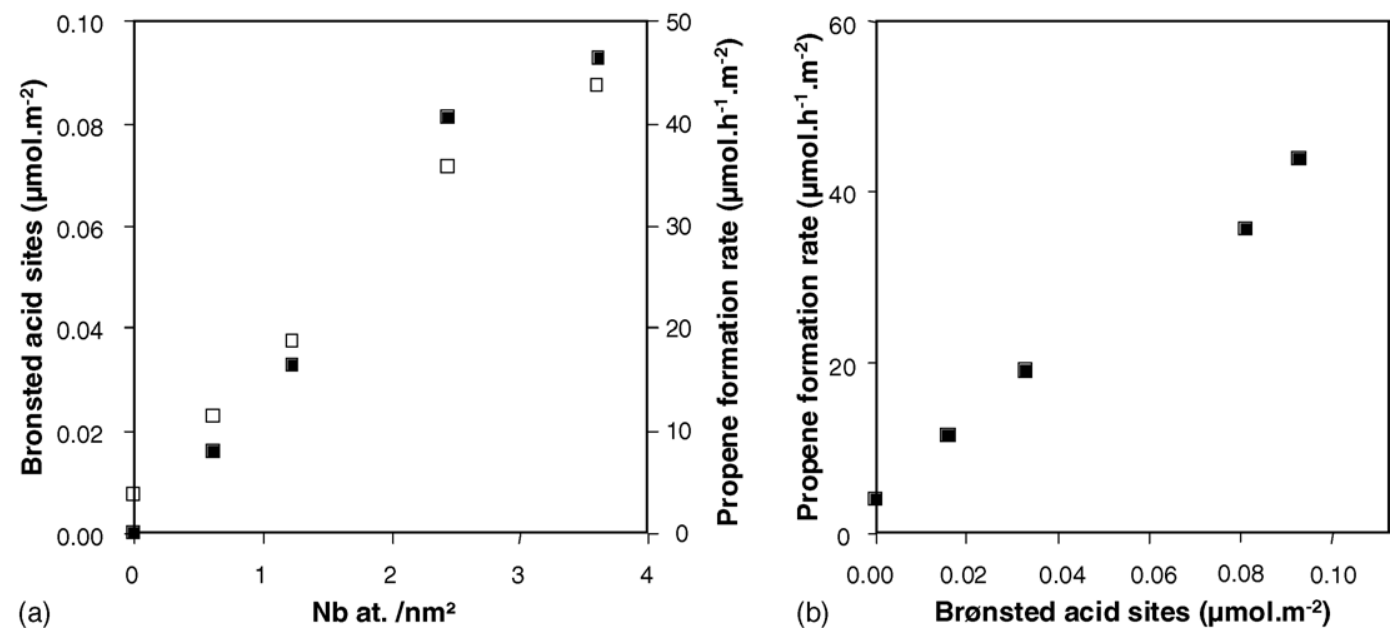

Fig. 7. (a) Propene formation rate at $473 \mathrm{~K}(\square)$ and abundance of weak Brønsted acid sites determined by desorption of lutidine at $523 \mathrm{~K}(\boldsymbol{\square}) \mathrm{vs}$. $\mathrm{Nb}$ density of $\mathrm{NbO} \mathrm{O}_{x} /$ $\mathrm{TiO}_{2}$ catalysts; (b) propene formation rate vs. abundance of Brønsted acid sites for $\mathrm{NbO}_{x} / \mathrm{TiO}_{2}$ catalysts. 
that of propene formation rate. For these solids, catalytic activity at $473 \mathrm{~K}$ appears to be related to the amount of Brønsted acid sites of medium acidity (obtained after lutidine desorption at $523 \mathrm{~K}$ ). This relationship can be attributed to the fact that since the reaction is carried out at higher temperature, moderate acidity is probably sufficient to achieve propanol dehydration.

\subsection{Comparison of the two systems}

\subsubsection{Influence of the supported metal loading}

The catalytic activity of $\mathrm{WO}_{x} / \mathrm{TiO}_{2}$ and $\mathrm{NbO}_{x} / \mathrm{TiO}_{2}$ catalysts was measured, respectively, at 403 and $473 \mathrm{~K}$ (Fig. 5). The W-containing system exhibited a behavior similar to that reported for the zirconia-supported $\mathrm{WO}_{x}$ and $\mathrm{NbO}_{x}$ systems [12-15], namely, the presence of a threshold of $\mathrm{W}$ surface density for the appearance and development of activity, followed by a steady increase in activity with increasing $\mathrm{W}$ surface density. In contrast, no such threshold was observed for the $\mathrm{NbO}_{x} / \mathrm{TiO}_{2}$ system. Up to $3.4 \mathrm{Nb}$ atom $\mathrm{nm}^{-2}$, the rate of propene formation increases progressively with increasing $\mathrm{Nb}$ content (Fig. 5b).

The study of the development of Brønsted acidity of both systems with $\mathrm{W}$ or $\mathrm{Nb}$ surface density indicates a parallel evolution to that of the rate of propene formation (Figs. 6a and 7a). This similarity is illustrated in Figs. $6 \mathrm{~b}\left(\mathrm{WO}_{x} / \mathrm{TiO}_{2}\right)$ and $7 \mathrm{~b}$ $\left(\mathrm{NbO}_{x} / \mathrm{TiO}_{2}\right)$, which show a direct relation between the abundance of Brønsted acid sites determined by desorption of lutidine and the rate of formation of propene. Thus, the absence of threshold of $\mathrm{Nb}$ surface density for the development of catalytic activity noted for the $\mathrm{NbO}_{x} / \mathrm{TiO}_{2}$ is reflected in a similar development of Brønsted acid sites. The direct relation between the abundance of Brønsted acid sites and the rate of propene formation suggests that the catalytic activity at a given temperature is associated with the abundance of Brønsted acid sites. This observation is consistent with our previous study of zirconia-supported $\mathrm{W}$ [13] and $\mathrm{Nb}$ [15] systems where a direct relation between the evolution of these two parameters has been evidenced.

\subsubsection{Influence of the nature of the supported phase}

As previously indicated, because of the drastic difference in the catalytic performance of $\mathrm{W}$ and $\mathrm{Nb}$ systems, the activity measurements were conducted, respectively, at 403 and $473 \mathrm{~K}$. At $403 \mathrm{~K}$, the rate of propene formation for $\mathrm{Nb}$-based catalysts was essentially negligible (Fig. 8a). The important difference in the activity of the two systems (ca. two orders of magnitude) may be attributed, in part, to the difference in the strength of Brønsted acid sites. In effect, lutidine desorption results at $573 \mathrm{~K}$ (Fig. 8b) indicate that only catalysts active at $403 \mathrm{~K}$ (Fig. 8a) exhibited relatively strong Brønsted acidity (i.e. capable of retaining lutidine at $573 \mathrm{~K}$ ). In contrast, catalysts inactive at this temperature do not exhibit such sites. Note that these observations are consistent with previous results from our group relative to the zirconia-supported $\mathrm{W}$ and $\mathrm{Nb}$ systems [15].

\subsubsection{Molecular structure of $W$ and $N b$ species: origin of the active site}

The characterization of $\mathrm{WO}_{x} / \mathrm{TiO}_{2}$ and $\mathrm{NbO}_{x} / \mathrm{TiO}_{2}$ by XRD and Raman spectroscopy indicates the absence of bulk $\mathrm{WO}_{3}$ and $\mathrm{Nb}_{2} \mathrm{O}_{5}$ phases. Only bands attributed to surface tungstates and niobates were detected (Figs. 1 and 2). In a previous study of $\mathrm{WO}_{x} / \mathrm{ZrO}_{2}$ [13] and $\mathrm{NbO}_{x} / \mathrm{ZrO}_{2}$ [15] systems, the creation and development of Brønsted acid sites were associated with the appearance and development of "extensively" polymerized surface tungstates and niobates. In line with this interpretation, one can propose that in the case of the corresponding titaniasupported systems, Brønsted acid sites active for the reaction of isopropanol dehydration are equally associated with the presence and development of these species. The difference in the observed behavior of the $\mathrm{NbO}_{x} / \mathrm{TiO}_{2}$ (i.e, absence of minimum loading for the appearance and development of the catalytic activity and Brønsted acidity) can, thus, be attributed
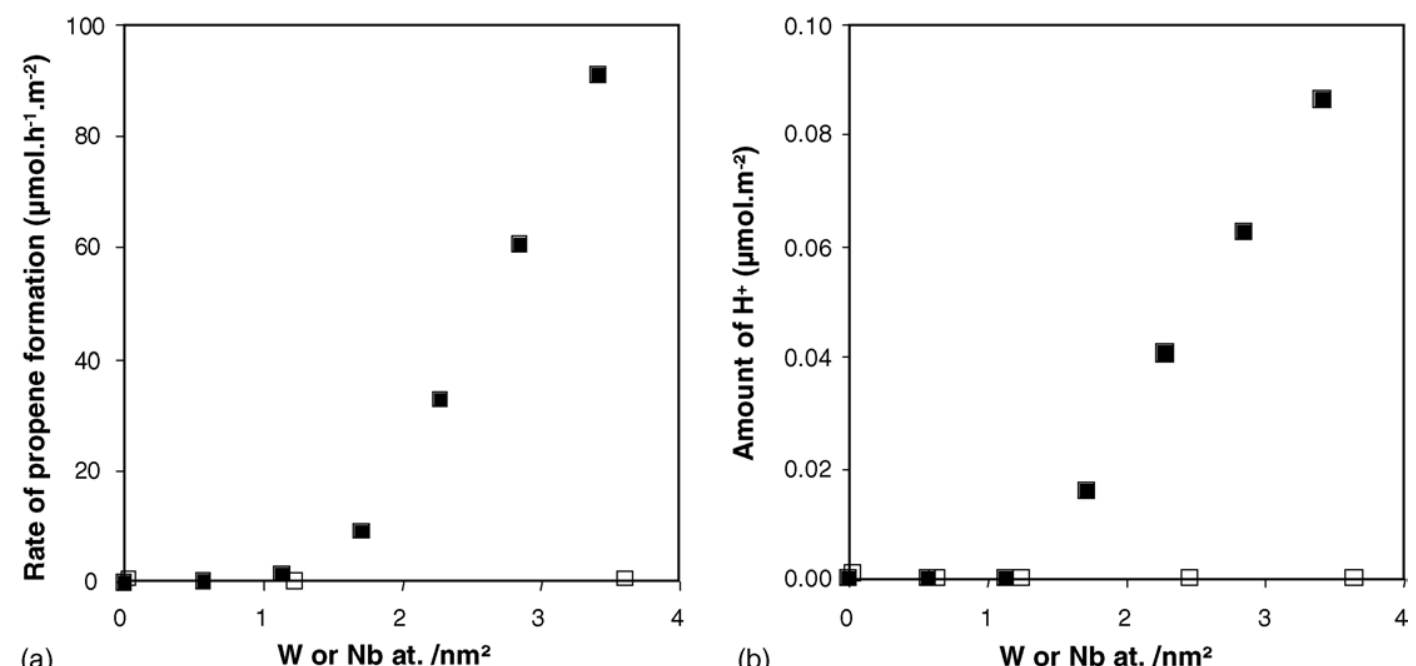

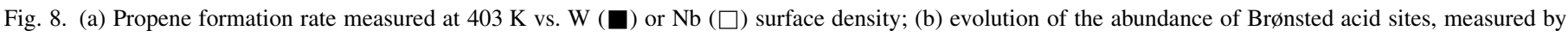
lutidine desorption at $573 \mathrm{~K}$, as a function of $\mathrm{W}(\square)$ or $\mathrm{Nb}(\square)$ surface density. 
to the formation of "extensively" polymerized niobates species for low $\mathrm{Nb}$ surface density.

\section{Conclusions}

The development of acidity and catalytic activity for propan2-ol dehydration with increasing the surface density of the deposited phase was studied for two series of catalysts, $\mathrm{WO}_{x} /$ $\mathrm{TiO}_{2}$ and $\mathrm{NbO}_{x} / \mathrm{TiO}_{2}$.

Characterization of both systems by X-ray diffraction and Raman spectroscopy studies did not show evidence of bulk metal oxide formation.

The acidity was monitored by adsorption of 2,6-dimethylpyridine (2,6-lutidine) followed by infrared spectroscopy. Relatively strong Brønsted acid sites were detected for $\mathrm{WO}_{x} /$ $\mathrm{TiO}_{2}$ catalysts. These sites only developed above a threshold of $1.1 \mathrm{~W}$ atom $\mathrm{nm}^{-2}$. For $\mathrm{NbO}_{x} / \mathrm{TiO}_{2}$ catalysts, only moderate Brønsted acidity developed with $\mathrm{Nb}$ addition.

The catalytic activity was tested for the reaction of isopropanol dehydration. At a reaction temperature of $403 \mathrm{~K}$, $\mathrm{WO}_{x} / \mathrm{TiO}_{2}$ catalysts were inactive for a surface density of $\mathrm{W} \leq 1.1 \mathrm{~W}$ atom $\mathrm{nm}^{-2}$. Above this loading, the activity increased progressively with increasing W content. Similar evolution was observed for the abundance of relatively strong Brønsted acid sites (i.e, able to retain 2,6-lutidine at $573 \mathrm{~K}$ ).

In contrast, $\mathrm{NbO}_{x} / \mathrm{TiO}_{2}$ catalysts were essentially inactive at this reaction temperature and a higher reaction temperature ( $473 \mathrm{~K})$ was required to reach a comparable catalytic activity. No threshold of $\mathrm{Nb}$ loading for the development of catalytic activity was observed. Similar behavior was evidenced for the abundance of medium strength Brønsted acid sites (able to retain 2,6-lutidine at $523 \mathrm{~K}$ ). For both systems, a direct correlation between the catalytic activity and the abundance of Brønsted acid sites was observed.

\section{Acknowledgements}

The Van Gogh exchange Program is gratefully acknowledged for a grant. Thanks are due to Mrs. M.-N. Metzner (Lab. SIFCOM, UMR CNRS 6176, ENSICAEN, Université de Caen) for performing the XRD measurements.

\section{References}

[1] T. Yamagushi, Y. Tanaka, K. Tanabe, J. Catal. 65 (1980) 442.

[2] S. Meijers, L.H. Gielgens, V. Ponec, J. Catal. 156 (1995) 147.

[3] D.G. Barton, S.L. Soled, G.D. Meitzner, G.A. Fuentes, E. Iglesia, J. Catal. 181 (1999) 57.
[4] M. Scheithauer, T.-K. Cheung, R.E. Jentoft, R.K. Grasselli, B.C. Gates, H. Knözinger, J. Catal. 180 (1998) 1.

[5] S. Eibl, R.E. Jentoft, B.C. Gates, H. Knözinger, Phys. Chem. Chem. Phys. 2 (2000) 2565.

[6] J.-M. Jehng, I.E. Wachs, Catal. Today 8 (1990) 37.

[7] L.L. Murrell, D.C. Grenoble, C.J. Kim, N.C. Dispenziere Jr., J. Catal. 107 (1987) 463.

[8] C.L.T. da Silva, V.L.L. Camorin, J.L. Zotin, M.L.R.D. Pereira, A.C. Fara Jr., Catal. Today 57 (2000) 209.

[9] S.B. Bukallah, Ph.D. Thesis, Vanderbilt University, Nashville, USA, 2000.

[10] P. Viparelli, P. Ciambelli, L. Lisi, G. Ruoppolo, G. Russo, J.C. Volta, Appl. Catal. A 184 (1999) 291

[11] M. Shirai, N. Ichikuni, K. Asakura, Y. Iwasawa, Catal. Today 8 (1990) 57.

[12] T. Onfroy, G. Clet, M. Houalla, Chem. Commun. (2001) 1378.

[13] T. Onfroy, G. Clet, M. Houalla, J. Phys. Chem. B 109 (2005) 3345.

[14] T. Onfroy, G. Clet, S.B. Bukallah, D.M. Hercules, M. Houalla, Catal. Lett. 89 (2003) 15.

[15] T. Onfroy, G. Clet, M. Houalla, J. Phys. Chem. B 109 (2005) 14588.

[16] F. Hilbrig, H. Schmelz, H. Knozinger, in: L. Guczi, F. Solymosi, P. Tetenyi (Eds.), Proceedings of the 10th ICC, Budapest, July 19-24, 1992, Stud. Surf. Sci. Catal., vol. 75, Elsevier, Amsterdam, 1993, p. 1351.

[17] P. Patrono, A. La Ginestra, G. Ramis, G. Busca, Appl. Catal. A 107 (1994) 249.

[18] G. Ramis, G. Busca, C. Cristiani, L. Lietti, P. Forzatti, F. Bregani, Langmuir 8 (1992) 1744.

[19] A. Gutièrrez-Alejandre, P. Castillo, J. Ramirez, G. Ramis, G. Busca, Appl. Catal. A216 (2001) 181.

[20] J. Engweiler, J. Harf, A. Baiker, J. Catal. 159 (1996) 259.

[21] J. Datka, A.M. Turek, J.-M. Jehng, I.E. Wachs, J. Catal. 135 (1992) 186.

[22] R.A. Spurr, H. Myers, Anal. Chem. 29 (1957) 760.

[23] T. Onfroy, G. Clet, M. Houalla, Microporous Mesoporous Mater. 82 (2005) 99

[24] N. Vaidyanathan, M. Houalla, D.M. Hercules, Surf. Interface Anal. 26 (1998) 415.

[25] B. Zhao, X. Xu, J. Gao, Q. Fu, Y. Tang, J. Raman Spectrosc. 27 (1996) 549.

[26] R.M. Pittman, A.T. Bell, J. Phys. Chem. 97 (1993) 12178.

[27] R.B. Quincy, M. Houalla, D.M. Hercules, Fresenius J. Anal. Chem. 346 (1993) 676

[28] J.-M. Jehng, I.E. Wachs, J. Phys. Chem. 95 (1991) 7373.

[29] N. Vaidyanathan, D.M. Hercules, M. Houalla, Anal. Bioanal. Chem. 373 (2002) 547.

[30] S.S. Chan, I.E. Wachs, L.L. Murrell, L. Wang, W.K. Hall, J. Phys. Chem. 88 (1984) 5831

[31] M.A. Vuurman, I.E. Wachs, A.M. Hirt, J. Phys. Chem. 95 (1991) 9928.

[32] R. Brayner, F. Bozon-Verduraz, Phys. Chem. Chem. Phys. 5 (2003) 1457.

[33] J.-M. Jehng, I.E. Wachs, Chem. Mater. 3 (1991) 100.

[34] J.-M. Jehng, I.E. Wachs, J. Mol. Catal. 67 (1991) 369.

[35] C. Lahousse, A. Aboulayt, F. Maugé, J. Bachelier, J.-C. Lavalley, J. Mol. Catal. 84 (1993) 283.

[36] A. Travert, O.V. Manoilova, A.A. Tsyganenko, F. Maugé, J.-C. Lavalley, J. Phys Chem. B 106 (2002) 1350

[37] J.R. Sohn, J.H. Bae, Kor. J. Chem. Eng. 17 (2000) 86. 